\title{
Randomized clinical trial of a calcium supplement for improvement of health in dairy cows in early lactation
}

\author{
Cynthia L. Miltenburg, ${ }^{*}$ Todd F. Duffield, ${ }^{*}$ Dorothee Bienzle, $†$ Elizabeth L. Scholtz, ${ }^{*}$ and Stephen J. LeBlanc ${ }^{* 1}$ \\ *Department of Population Medicine, and \\ †Department of Pathobiology, University of Guelph, ON, Canada N1G 2W1
}

\begin{abstract}
Prophylactic Ca supplementation immediately after calving is a common strategy to prevent clinical and subclinical hypocalcemia in parturient dairy cows. The objective of this study was to evaluate the effect of prophylactic administration of an injected Ca supplement on blood $\mathrm{Ca}$ concentration at 24 and $48 \mathrm{~h}$ after treatment, incidence risk of clinical disease and culling, milk production in early lactation, and probability of pregnancy at first insemination. Cows without signs of visible milk fever $(\mathrm{n}=984)$ from 7 farms were blocked by parity and randomly assigned to receive either $\mathrm{Ca}$ gluconate $(35 \% \mathrm{wt} / \mathrm{vol})$ in combination with $\mathrm{Ca}$ glucoheptonate (10\% wt/vol; TheraCalcium, Vétoquinol Canada Inc., Lavaltrie, Quebec) or a placebo (medication vehicle solution with no Ca) at first contact with each cow after calving and again 12 to $24 \mathrm{~h}$ later. Each dose was $120 \mathrm{~mL}$ injected subcutaneously over 2 sites. Total serum Ca concentration (tCa) was measured from coccygeal blood samples before (time 0) and 24 and $48 \mathrm{~h}$ after first treatment in a subsample of cows $(\mathrm{n}=129)$. Blood $\beta$-hydroxybutyrate concentrations were measured from all cows twice between 3 and 16 $\mathrm{d}$ in milk at weekly visits and cows were evaluated for vaginal discharge once between 28 and $42 \mathrm{~d}$ in milk. Disease events, production data from the first 3 Dairy Herd Improvement milk tests, reproduction, and culling data were collected from each herd. For cows that had received 1 injection of Ca before the blood sample at 24 $\mathrm{h}(\mathrm{n}=95)$, tCa was significantly higher in the treated cows: mean \pm standard error, $2.03 \pm 0.03$ versus $1.90 \pm$ $0.03 \mathrm{mmol} / \mathrm{L}$, accounting for tCa at time of enrollment and a treatment by tCa at enrollment interaction. At $48 \mathrm{~h}$, no significant difference was found in tCa between treatment and control (mean $\pm \mathrm{SE}, 2.12 \pm 0.02$ and $2.10 \pm 0.03 \mathrm{mmol} / \mathrm{L}$, respectively). Cows treated with the $\mathrm{Ca}$ product were significantly less likely to have
\end{abstract}

Received January 28, 2016.

Accepted April 27, 2016.

${ }^{1}$ Corresponding author: sleblanc@uoguelph.ca received intravenous, subcutaneous, or oral supplemental Ca for exhibiting clinical signs of hypocalcemia than control cows (5.0 vs. 8.4\%). No effect was found of treatment on retained placenta, metritis, hyperketonemia, prevalence of purulent vaginal discharge, culling from the herd, early lactation production, probability of pregnancy to first artificial insemination, or time to pregnancy. With this subcutaneous prophylactic Ca treatment regimen, blood Ca levels were temporarily increased at $24 \mathrm{~h}$ after treatment, but no effect was observed of supplemental $\mathrm{Ca}$ on the risk of disease or culling, milk production, or reproductive performance. Key words: hypocalcemia, calcium supplement, periparturient, transition, disease

\section{INTRODUCTION}

Milk fever (MF) or clinical hypocalcemia is a metabolic disorder that results when homeostatic mechanisms fail to maintain blood Ca levels around calving to the point that visible signs of muscle weakness occur. The lactational incidence risk (LIR) has been reported to range from 3 to $6 \%$ of cows of all parities depending on geographical location (DeGaris and Lean, 2008). McLaren et al. (2006) reported a mean MF incidence of $4.2 \%$ in a sample of 48 dairy herds in Ontario, Canada. Calcium is critical for muscle and nerve function and reduced blood Ca compromises skeletal muscle strength and gastrointestinal motility, which can predispose cows to reduced DMI, increased incidence of metabolic diseases, and decreased milk yield (Oetzel, 2013). Milk fever has also been associated with immune suppression by impairing the activity of mononuclear blood cells (Kimura et al., 2006).

Subclinical hypocalcemia (SCH) as a distinct but related disease entity to MF has been recognized more recently and been the focus of much research. The principle of $\mathrm{SCH}$ is that below certain thresholds of blood Ca concentration undesirable consequences occur despite an absence of visible signs. The prevalence of plasma Ca between 1.5 and $2.0 \mathrm{mmol} / \mathrm{L}$ within $48 \mathrm{~h}$ postpartum, which is assumed to correspond to $\mathrm{SCH}$, 
has been reported to vary from 25 to $54 \%$ depending on parity (Reinhardt et al., 2011). Subclinical hypocalcemia around calving has been associated with increased odds of a displaced abomasum (DA), greater odds of culling, reduced milk yield in early lactation, and a difference in early lactation fatty acid metabolism (Chapinal et al., 2011; Roberts et al., 2012; Chamberlin et al., 2013). Martinez et al. (2012) found that cows with a blood Ca concentration less than $2.15 \mathrm{mmol} / \mathrm{L}$ at any point during the first 3 DIM had lower concentrations of neutrophils, impaired neutrophil function, and increased incidence of metritis compared with cows that maintained blood Ca above $2.15 \mathrm{mmol} / \mathrm{L}$.

The consequences of MF and the inability to rapidly and practically identify SCH have emphasized the importance of prevention. Prior to calving, prevention strategies are principally focused on the DCAD of the precalving ration. A large number of Ca supplementation products that can be given orally or subcutaneously have been promoted to producers as additional insurance against hypocalcemia. Administration to all cows or all multiparous cows after calving has been instituted in many herds. Some oral supplements such as $\mathrm{CaCl}_{2}$ are acidifying in addition to providing rapidly absorbed Ca. Given as a drench, gel or paste, or as a component of a $\mathrm{Ca}$ bolus, several studies have shown that $\mathrm{CaCl}_{2}$ raises blood $\mathrm{Ca}$ for $12 \mathrm{~h}$ after administration (Goff and Horst, 2003; Sampson et al., 2009; Blanc et al., 2014). Subcutaneous administration of $500 \mathrm{~mL}$ of Ca borogluconate $(23 \% ; 10.5 \mathrm{~g}$ of $\mathrm{Ca}$ ) has been shown to increase blood $\mathrm{Ca}$ concentrations to about $120 \%$ of baseline for approximately $6 \mathrm{~h}$ after calving (Goff, 1999). Cows given $200 \mathrm{~mL}$ of Ca borogluconate (40\%; 6 $\mathrm{g}$ of $\mathrm{Ca}$ ) were more likely to have blood Ca concentrations above $2.0 \mathrm{mmol} / \mathrm{L} 12 \mathrm{~h}$ after treatment (MoheffiFani and Azadnia, 2012).

Several studies have examined the effects of $\mathrm{Ca}$ supplements on disease, production, and reproduction of parturient dairy cows. A controlled trial administering $\mathrm{CaCl}_{2}$ gel prophylactically to 204 Holstein cows in one herd found treated cows had higher serum Ca concentrations at d 1 and 2 after calving and reduced incidence of MF and DA (Oetzel, 1996). Conversely, Hernandez et al. (1999), using 60 cows from a single large dairy [including one-third purposively selected with retained placenta $(\mathbf{R P})$ ], did not find a significant effect of $\mathrm{CaCl}_{2}$ gel on serum $\mathrm{Ca}$ or the incidence of metritis or DA; time to first insemination, pregnancy status after first insemination and milk production were similarly unaffected. However, differences in these outcomes would be extremely difficult to establish with such a limited sample size. Melendez et al. (2003) examined $\mathrm{CaCl}_{2}$ gel and a second Ca propionate supplement on 479 cows in a single herd feeding anionic salts and found no treatment effect on MF, RP, metritis, ketosis, DA, pregnancy at first service, overall pregnancy rate, and services per pregnancy. More recently, a controlled trial involving 927 multiparous cows from 2 herds evaluated the effect of supplementation with oral $\mathrm{Ca}$ boluses after calving and found that among cows with a previous lactation mature-equivalent milk production greater than $105 \%$ of herd average, supplementation was associated with $2.9 \mathrm{~kg}$ more milk at first DHIA test after calving (Oetzel and Miller, 2012). Cows that were lame in the dry period that received the Ca boluses had fewer total health events in the first $30 \mathrm{~d}$ after calving; however, there was no treatment effect on the other disease, production, or reproduction outcomes examined.

The objective of this study was to evaluate the effect of prophylactic administration of a commercially available injected combination of $\mathrm{Ca}$ gluconate and $\mathrm{Ca}$ glucoheptonate on the incidence of clinical disease and culling, milk production in early lactation, and probability of pregnancy at first insemination. In addition, the effect of administration of the product on blood $\mathrm{Ca}$ concentrations was evaluated at 24 and $48 \mathrm{~h}$ after treatment, in cows without clinical hypocalcemia.

\section{MATERIALS AND METHODS}

\section{Study Population}

The study was conducted on 7 commercial dairy farms in Ontario, Canada, from June 2013 to March 2014. Herd size ranged from 40 to 500 lactating cows. Herds were purposively selected on proximity to the University of Guelph and willingness to comply with the $\mathrm{Ca}$ supplementation protocols. To be eligible for enrollment, study herds had to be subscribed to a milk recording service (Canwest DHI), administer Ca supplementation according to protocol directions to all cows calving in the herd during the study period, and refrain from use of other forms of prophylactic Ca supplementation for the duration of the study. All herds fed a TMR and prepartum cows did not receive supplemental anionic salts such that the calculated DCAD of all diets was positive. All herds consented to a study protocol that had been reviewed and approved by the University of Guelph Animal Care Committee.

\section{Study Design and Data Collection}

Cows were enrolled in the study by farm personnel as soon as observed after calving. Because personnel were not typically in the barn through the late night, the greatest time from calving to enrollment was $8 \mathrm{~h}$. Cows 
that had calved were categorized within each herd as being in first or second parity, or third and greater parity. Within each parity group, cows were randomly assigned to receive the Ca supplementation product or a placebo (identically packaged product vehicle without Ca). Farm personnel administered and recorded experimental treatments according to randomized assignment sheets and were blinded to the treatment given. Each treatment was contained in one $250-\mathrm{mL}$ bottle, identified with a number. Treatments were randomly allocated and balanced in sets of 10 bottles. Cow ID, parity, calving ease, and time of treatment administration were recorded by farm personnel. A sample size of 1,000 cows was planned to detect differences between 6.5 and $3 \%$ for the incidence of DA, 25 and $18 \%$ prevalence of subclinical ketosis, 16 and $10 \%$ prevalence of purulent vaginal discharge (PVD), 42 and 50\% cows pregnant by 120 DIM in the control and treatment groups, respectively, and a $1 \mathrm{~kg} / \mathrm{d}$ milk yield difference (SD of $6 \mathrm{~kg} / \mathrm{d}$ ) with $95 \%$ confidence and $80 \%$ power. The expected incidence in the control group was based on average incidence risks reported in some of our recent studies. Given the paucity of studies showing effects of treatment with $\mathrm{Ca}$ on these outcomes, the differences in the treated group were chosen to be sufficiently large as to be practically important.

Cows in the treated group received $\mathrm{Ca}$ gluconate (35\% wt/vol) in combination with Ca glucoheptonate (10\% wt/vol) for a total of $9.46 \mathrm{~g}$ of Ca (TheraCalcium, Vétoquinol Canada Inc., Lavaltrie, Quebec) divided into 2 doses, injected at first handling as soon as possible after calving, and again 12 to $24 \mathrm{~h}$ later. The target time for the second injection was $12 \mathrm{~h}$, with allowance to avoid treatments through the night. Each dose was $120 \mathrm{~mL}$ given over 2 sites (60 mL per site) subcutaneously. This dose regimen reflected common use of the product at the time. A pilot study in 22 cows (S. J. LeBlanc, unpublished data) demonstrated no difference in blood total $\mathrm{Ca}$ concentration at 12 and $24 \mathrm{~h}$ after treatment between cows that received $250 \mathrm{~mL}$ at once compared with divided administration as used here. Cows in the control group received a similar volume of placebo (medication vehicle solution with no active ingredient) at the same time points as treated cows. During the first $10 \mathrm{wk}$ of the study, a negative control (no intervention) was used because the production of the placebo was delayed. During this time, producers enrolled cows as a treatment or negative control according to randomized assignment sheets but were not blinded.

Cows displaying signs of MF or injury resulting in inability to rise at time of first examination after calving were excluded from enrollment. Otherwise, all cows that calved were included in the study. If cows enrolled in the study began to show signs of clinical hypocalcemia, farm personnel recorded any supplemental Ca treatments given to the cow.

Prior to receiving treatment or placebo, whole blood samples were collected for measurement of $\mathrm{Ca}$ on 5 of the 7 farms by the farm personnel. Whole blood was collected from the coccygeal vein using a 20 -gauge, 1 -inch $(2.54 \mathrm{~cm})$ hypodermic needle (BD Vacutainer Precision Glide, Becton, Dickinson and Co., Franklin Lakes, NJ) into sterile glass blood collection tubes without anticoagulant (BD Vacutainer, Becton, Dickinson and Co.). Samples were immediately refrigerated on farm. Serum was subsequently separated by centrifugation at 1,500 $\times g$ for 15 min at $20^{\circ} \mathrm{C}$ and stored at $-20^{\circ} \mathrm{C}$. The length of refrigeration before serum separation ranged from $4 \mathrm{~h}$ to $3 \mathrm{~d}$. This storage and sampling protocol was validated by collecting 4 tubes of whole blood from 20 periparturient cows and refrigerating for 1, 24, 48, or $72 \mathrm{~h}$ after collection before centrifugation. The mean concentration of Ca changed minimally $(0.02 \mathrm{mmol} / \mathrm{L})$ after $72 \mathrm{~h}$ of refrigerated storage. All serum was submitted to the Animal Health Laboratory, University of Guelph, for analysis of total Ca concentration (tCa) and was measured using the Cobas Ca Gen 2 kit (Roche Diagnostics, Indianapolis, IN). The analytical sensitivity of the Ca assay is $0.2 \mathrm{mmol} / \mathrm{L}$ and the intra-assay coefficient of variation was $1.49 \%$.

Additional whole blood samples were collected from a subset of 144 cows 24 and $48 \mathrm{~h}$ after enrollment according to the collection procedure above. This sample size was designed to detect a difference of $0.2(\mathrm{SD}=$ $0.35) \mathrm{mmol} / \mathrm{L}$ tCa between groups. These samples represented all the animals that were enrolled from herds 2 and 4 and a convenience sample from herds 1 and 5 when a technician was available to take the samples on weekdays. These samples were analyzed for tCa.

Herds were visited weekly on the same day of the week by research technicians. All cows that had been enrolled by farm personnel and were between 3 and 16 DIM had a blood sample collected for blood BHB measurement using the Precision Xtra meter (Abbott Laboratories, Abbott Park, IL). This resulted in all cows being tested twice, 1 wk apart. The Precision Xtra meter was previously validated for use in cattle (Iwersen et al., 2009). Blood was collected from the coccygeal vessels via a 20 -gauge, $2.54-\mathrm{cm}$ needle, and 3 -mL syringe and ketone testing was performed immediately. The blood BHB concentration displayed was subsequently recorded. At first visit between 3 and 9 DIM, all cows were assigned a BCS by 1 of 4 trained technicians, according to Ferguson et al. (1994).

At the weekly visit, cows between 28 and 42 DIM were evaluated for vaginal discharge using a Metricheck device (Metricheck, Simcro, Hamilton, New Zealand) 
validated by McDougall et al. (2007). The vulva of each cow was cleaned and the Metricheck inserted and advanced to the cranial vaginal fornix and then slowly retracted caudally. Material that remained on the concave surface of the device was classified according to the scoring system outlined by Sheldon et al. (2006).

Disease, production, reproduction, and culling data for each herd were exported from DairyComp305 (Valley Ag Software, Tulare, CA) at the end of the study. Milk weight, percent fat, percent protein, SCC, and linear score were recorded from the first, second, and third DHIA tests for each animal enrolled. The outcome variable projected mature-equivalent $305 \mathrm{~d}$ milk yield, which predicts production for a 305-d lactation based on current test day weights adjusted for season and age, was collected from the third DHIA test. Previous lactation mature-equivalent 305 -d yield was also obtained for cows that were second parity and greater.

The date of first insemination and date of pregnancy were exported from DairyComp305 at the end of the study. A cut-off date of $7 \mathrm{mo}(214 \mathrm{~d})$ after the last day of enrollment in the study was used to end the period during which cows could be recorded as pregnant. Herds 2 and 6 did not use DairyComp305 to record reproductive events so breeding dates were obtained from farm records. Dates of removal from the herd and the recorded reason for exit were also exported from DairyComp305. All herds were provided with standardized definitions of MF, RP, metritis, and DA (LeBlanc et al., 2002). Herds 1, 3, 4, 5, and 7 used DairyComp305 to record disease events and this information was exported. Farm records from herds 2 and 6 were consulted weekly and recorded by researchers.

\section{Statistical Analysis}

All statistical analyses were performed in SAS (version 9.4, SAS Institute Inc., Cary, NC) considering the cow as the unit of interest. Of the 984 cows in the study, blood samples were collected from 659 animals before treatment. Two blood samples with values close to zero were excluded as laboratory error. Clinical disease, culling, milk production, and reproduction outcomes were examined for all cows enrolled in the study $(\mathrm{n}=984)$ and were modeled again for the 657 cows with pre-enrollment blood samples offering tCa0 as a covariate. All models were initially built testing placebo controls in separate models from the negative controls used for the first $10 \mathrm{wk}$ of the study, before receiving the placebo. However, no differences in treatment effects were found in any of the models; therefore, placebo controls were combined with negative controls to make one control group for comparison.

\section{Blood Ca Dynamics Models}

Among the sample of cows with additional blood samples, the outcomes of interest were blood Ca concentration at 24 and $48 \mathrm{~h}$ after enrollment and whether blood Ca concentration was above a cut point of 2.15 $\mathrm{mmol} / \mathrm{L}$ at 24 and $48 \mathrm{~h}$. Blood Ca concentrations at 24 and $48 \mathrm{~h}$ were examined for normality. Parity was classified as 1,2 , or $\geq 3$. Descriptive statistics were generated using the PROC MEANS, PROC TTEST, and PROC FREQ procedures of SAS. Farm, season, calving difficulty, twins, parity, and pretreatment $\mathrm{Ca}$ (Cat0) were examined for association with the selected outcomes using contingency tables and the chi-squared statistic for categorical variables and univariable linear regression for continuous variables using PROC MIXED. Any variable associated with the outcome with $P<$ 0.2 was offered to multivariable models. Treatment was retained in all models regardless of $P$-value. All 2-way interactions between treatment and the covariates in the final model were tested and retained if significant.

The effect of treatment on blood Ca concentration over time until $48 \mathrm{~h}$ after enrollment was evaluated using a linear mixed model with cow as a repeated measure (PROC MIXED in SAS) and blood Ca concentrations at 24 and $48 \mathrm{~h}$ after administration were evaluated individually using linear regression models (PROC MIXED in SAS). Parity and blood Ca concentration at the time of enrollment (tCa0) had a Pearson correlation coefficient of -0.69 and so only tCa0 was offered to the models. Recognizing that blood Ca concentration is often not available to producers or practitioners, each model was built a second time with parity as surrogate for tCa0. The effect of treatment on tCa being above the defined cut point of $2.15 \mathrm{mmol} / \mathrm{L}$ at 24 and $48 \mathrm{~h}$ was evaluated using a logistic regression model (GLIMMIX procedure).

\section{Clinical Disease and Culling Models}

The outcomes of interest were the occurrence of RP, DA, metritis, visible signs of MF (requiring additional Ca therapy), hyperketonemia at wk 1,2, or both after calving, PVD at 5 wk postpartum, and removal from the herd within the first 60 DIM. Producers recorded any additional Ca given if they judged that a cow was entering stage I hypocalcemia (e.g., weak, cold, staggering, or difficulty rising). Metritis was defined as visible systemic illness with fetid vaginal discharge and rectal temperature $>39.5^{\circ} \mathrm{C}$ and was diagnosed by farm personnel. Hyperketonemia was defined as BHB $\geq 1.2$ mmol/L (Raboisson et al., 2014) at one or both of the weekly tests. Cows with a PVD (score $\geq 2$ out of 3 ) were 
considered positive for PVD. Descriptive statistics were generated using PROC FREQ and PROC MEANS in SAS. Each variable was examined for association with the outcomes and any variable with $P<0.2$ was offered to multivariable mixed logistic regression models using PROC GLIMMIX in SAS. Variables were removed manually by backward stepwise elimination in order of highest $P$-value until only variables associated with the outcome remained $(P<0.05)$. With each variable removal, evidence of confounding was determined by a change in coefficient for treatment of $>20 \%$. Variables meeting this criterion were left in the model regardless of statistical significance.

The effect of treatment on clinical disease and culling was examined using multivariable logistic regression models with farm offered as a fixed effect. Treatment was retained in all models regardless of $P$-value. Interactions were tested with treatment and retained if biologically plausible and significant.

\section{Milk Production and Reproductive Success Models}

The outcomes of interest for milk production were 24-h yield at each of the first, second, and third DHIA tests, 24-h production over the 3 first tests in the lactation, and predicted 305-d milk yield at third test. All variables with a univariable association with the outcome $(P \leq 0.2)$ in a univariable mixed regression model were offered to the multivariable model and built using the backward elimination process described previously. Twenty-four hour production at each test and projected milk 305-d milk yield at the time of the third test were modeled using linear regression. Production over the 3 tests was modeled using linear regression with cow as a repeated measure (PROC MIXED). Treatment was retained in all models regardless of $P$-value, and all 2-way interactions with treatment were tested and retained if significant $(P$-value $<0.05)$.

The probability of pregnancy at first insemination was modeled using a multivariable logistic regression model with farm as a fixed effect (GLIMMIX procedure). Backward elimination was used until only significant variables or their interactions remained $(P<0.05)$. A Cox proportional hazard model (PHREG procedure) considering the time to pregnancy with herd as a fixed effect was used to evaluate the effect of treatment on the interval from calving to subsequent pregnancy. Cows were censored at the time of pregnancy, date of culling, or reaching the data collection end date. A maximum observation time of $300 \mathrm{~d}$ was used.

\section{RESULTS}

Blood samples were collected at 0, 24, and $48 \mathrm{~h}$ from 144 cows from 4 herds. Fifteen animals that received additional $\mathrm{Ca}$ therapy by the farm personnel for exhibiting clinical signs of hypocalcemia were excluded from the analysis of tCa to assess blood Ca changes attributable to the treatment, for a total of 129 animals used in all blood Ca concentration models (Table 1). Descriptive statistics for the 129 animals in the subsample are in Table 2. No difference was found in the mean parity $(2.20 \pm 1.28$ vs. $2.10 \pm 1.18)$ or mean tCa0 (2.07 \pm 0.28 vs. $2.01 \pm 0.24 \mathrm{mmol} / \mathrm{L}$ ) between treatment and control groups $(P>0.3)$. However, more cows in the treatment group than the control group had serum $\mathrm{Ca}$ $\geq 2.15 \mathrm{mmol} / \mathrm{L}$ at enrollment (43 vs. $26 \%, P<0.05$ ). The proportion of cows above a biological threshold supported by Martinez et al. (2012) at each time point is outlined in Table 2. Cumulatively to $48 \mathrm{~h}, 72 \%$ of cows tested were below $2.15 \mathrm{mmol} / \mathrm{L}$ at one or more of 3 tests.

\section{Effect of Treatment on Blood Ca Concentration Over Time}

The repeated measures model of the effect of treatment on blood $\mathrm{Ca}$ concentration until $48 \mathrm{~h}$ after enrollment included treatment $(P<0.0001)$, time $(P<$

Table 1. Distribution of Holstein cows enrolled in a randomized controlled trial of an injectable Ca supplement administered within $8 \mathrm{~h}$ after calving ${ }^{1}$

\begin{tabular}{lccc}
\hline Farm & $\begin{array}{c}\text { Number of } \\
\text { animals enrolled }\end{array}$ & $\begin{array}{c}\text { Number of animals } \\
\text { with a blood sample } \\
\text { at enrollment }\end{array}$ & $\begin{array}{c}\text { Number of animals with } \\
\text { blood samples at 24 and } 48 \mathrm{~h} \\
\text { after enrollment }\end{array}$ \\
\hline 1 & 73 & 19 & 10 \\
2 & 74 & 70 & 65 \\
3 & 136 & 0 & 0 \\
4 & 34 & 30 & 24 \\
5 & 45 & 0 & 0 \\
6 & 81 & 507 & 0 \\
7 & 551 & 661 & 129 \\
Total & 994 & & 0 \\
\hline
\end{tabular}

${ }^{1}$ Blood samples for measurement of serum total Ca were collected from a subset of animals. 
$0.0001)$, blood Ca concentration at time $0(P<0.0001)$, and a treatment $\times$ time interaction $(P=0.001)$. As a result of the treatment $\times$ time interaction, total $\mathrm{Ca}$ concentration was examined at each time point separately.

\section{Effect of Treatment on Blood Ca Concentration After $24 h$}

In 96 cows, the 24-h blood sample was obtained immediately before the second treatment. However, in the remaining 33 cows, the 24 -h blood sample was collected after the second treatment. Therefore, 2 separate models were built. For cows that had received one injection, variables included in the model for total blood $\mathrm{Ca}$ at $24 \mathrm{~h}(\mathbf{t C a} 24)$ were treatment, $\mathrm{tCa} 0$, and a treatment $\times$ tCa0 interaction. Treatment significantly increased $\mathrm{tCa} 24$ (LSM $\pm \mathrm{SE}$ was $2.03 \pm 0.03$ in the treatment group and $1.90 \pm 0.03 \mathrm{mmol} / \mathrm{L}$ in the control group; $P=0.01)$. The interaction of pretreatment tCa with treatment is illustrated in Figure 1. Cows in the treatment group with lower tCa0 had a greater increase in tCa to $24 \mathrm{~h}$. In a similar model using parity as a covariate instead of tCa0, least squares means tCa24 was 0.20 $\mathrm{mmol} / \mathrm{L}$ higher in the treatment group $(2.04 \pm 0.03 \mathrm{vs}$. $1.84 \pm 0.03 \mathrm{mmol} / \mathrm{L} ; P<0.001$ ).

For cows that had received both treatment injections before the 24 -h blood sample $(\mathrm{n}=33)$, variables in the model for tCa24 were treatment and tCa0 $(P=$ 0.005 ). Least squares means were $2.17 \pm 0.04 \mathrm{mmol} / \mathrm{L}$ in the treated group and $2.07 \pm 0.05 \mathrm{mmol} / \mathrm{L}$ in the control group $(P=0.18)$. When parity replaced tCa0 as a covariate, the model was similar and tCa tended to be higher in the treatment group $(P=0.07)$ accounting for parity $(P=0.02)$; least squares means were $2.19 \pm$ 0.05 and $2.05 \pm 0.06 \mathrm{mmol} / \mathrm{L}$, respectively.

\section{Effect of Treatment on Blood Ca Concentration After $48 \mathrm{~h}$}

After $48 \mathrm{~h}$, no effect was found of treatment on tCa $(P=0.46)$ after accounting for tCa0 $(P<0.0001)$ or parity $(P<0.01)$ and farm as a fixed effect $(P=0.07)$. Least squares means were $2.12 \pm 0.02$ and $2.09 \pm 0.03$ $\mathrm{mmol} / \mathrm{L}$ for the treated and control groups, respectively.

\section{Effect of Treatment on the Proportion of Cows with Blood Ca Above a Biological Threshold}

Using the cows that had received one injection of treatment at $24 \mathrm{~h}(\mathrm{n}=96)$, a cut point of $2.15 \mathrm{mmol} / \mathrm{L}$ was used as an outcome due to its association with the risk of metritis and neutrophil function (Martinez et al., 2012). No significant difference was found between treatment groups in the proportion of cows $(36 \%)$ with a tCa24 greater than the cut point $(P=0.73)$, after accounting for tCa0 $(P<0.001)$. Similarly, at $48 \mathrm{~h}$ $(\mathrm{n}=129)$ no difference was found between treatment groups in the proportion of cows above the cut point $(P$ $=0.81)$ after accounting for tCa0 $(P<0.01)$.

\section{Clinical Trial}

A total of 994 cows were enrolled in the study; however, 10 cows did not receive the treatment according to the protocol and were therefore excluded from analysis. No adverse reactions were associated with treatment. The distribution of animals by treatment and parity is listed in Table 3. The distribution of pretreatment total blood Ca by parity is displayed in Figure 2. Thirtyseven animals had been removed from the herd and were unavailable for ketone sampling in wk 1 (3 to 9 DIM), and an additional 23 animals were not available

Table 2. Descriptive statistics for a subset of 129 animals from 4 herds enrolled in a randomized controlled trial of an injectable Ca supplement administered within $8 \mathrm{~h}$ after calving ${ }^{1}$

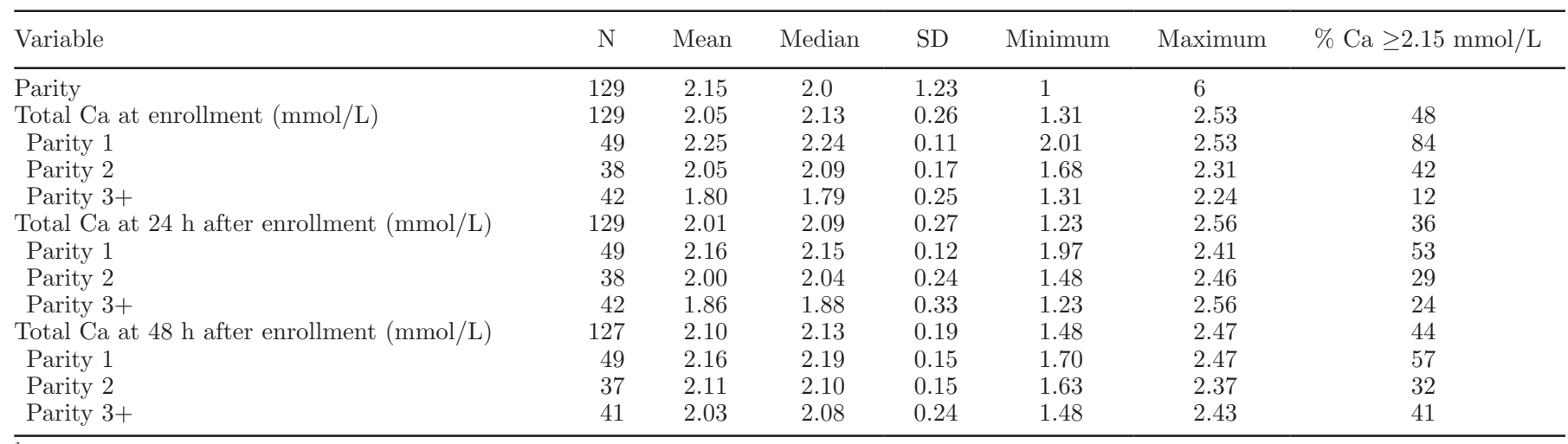

${ }^{1}$ Blood samples for measurement of serum total Ca were collected at 0, 24, and $48 \mathrm{~h}$ relative to enrollment. 
at wk 2 (10 to 16 DIM). At 28 to 42 DIM, 868 animals were available for Metricheck examination with losses due to death $(\mathrm{n}=25)$, culling $(\mathrm{n}=46)$, and sale for dairy $(\mathrm{n}=45)$.

\section{Effect of Treatment on Clinical Disease}

No differences were found in the LIR or cumulative incidence between groups for any of the clinical diseases recorded (Table 3). The recorded LIR of RP in the study population was $6.6 \%$. Treatment had no effect on the LIR of RP $(P=0.92)$ after accounting for farm $(P<0.0001)$, BCS $(P=0.06)$, and twins $(P<0.01)$. The recorded LIR of metritis in the study was $3.4 \%$. Treatment had no effect on the odds of metritis $(P=$ $0.13)$ after accounting for parity $(P<0.01)$ and calv- ing difficulty score $(P<0.01)$. Only 13 DA cases were observed during the study and therefore not enough to model the effect of treatment on DA.

\section{Effect of Treatment on Additional Ca Therapy}

Sixty-five animals (6.6\%) displayed clinical signs of hypocalcemia after enrollment and required treatment with additional Ca therapy. Therapies were producer or veterinarian directed and included one or more of intravenous, subcutaneous, or oral Ca. Of the animals treated, 29 cows (45\%) were treated with subcutaneous or oral Ca only and 36 cows $(55 \%)$ were treated with intravenous $\mathrm{Ca}$ with or without subcutaneous or oral Ca products. Variables retained in the model for effect of treatment on clinical hypocalcemia included parity

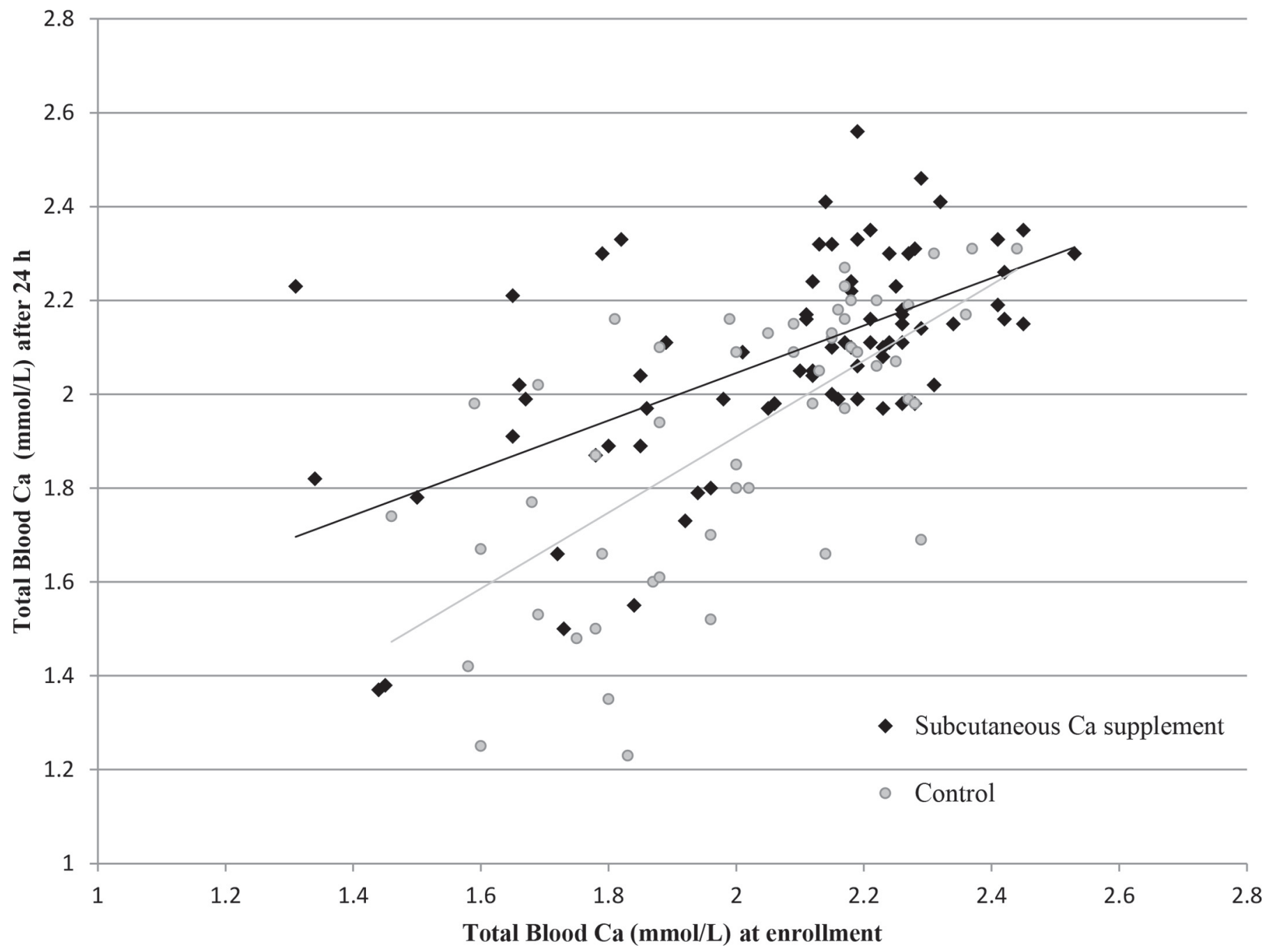

Figure 1. The interaction of injectable Ca supplementation with pretreatment blood Ca on blood total Ca $24 \mathrm{~h}$ after initial treatment in 96 Holstein cows from 4 herds that had received half $(120 \mathrm{~mL})$ of the total treatment at time of blood sampling. The LSM for blood total Ca concentration at $24 \mathrm{~h}$ after initial treatment was $0.13 \mathrm{mmol} / \mathrm{L}$ higher in the treatment group. 
and twins. Accounting for the effects of parity and twins, cows in the treatment group were significantly less likely to require additional Ca therapy than control cows (5.0 vs. $8.4 \% ; P=0.02$; Table 4 ).

\section{Effect of Treatment on Hyperketonemia, $P V D$, and Culling}

The prevalence of hyperketonemia at each of wk 1 and 2 was $14 \%$ with a cumulative incidence of $22 \%$ during the first $2 \mathrm{wk}$ of lactation. Variables retained in the wk 1 postpartum ketosis model included farm $(P<$ $0.0001)$, season $(P<0.0001)$, and parity $(P<0.0001)$. At wk 2 , farm $(P<0.0001)$, parity $(P<0.001)$, and season $(P=0.001)$ were retained. Treatment had no effect on the prevalence of subclinical ketosis in either week $(P>0.37)$, or cumulatively $(P=0.50)$ over the 2 wk (modeled with identical variables as wk 1 ).

The mean $\pm \mathrm{SD}$ time at which cows enrolled were examined for PVD was $33 \pm 3.4 \mathrm{~d}$. The prevalence of PVD was $13 \%$. Treatment had no effect on the prevalence of PVD $(P=0.21)$ after accounting for twins $(P$ $<0.01)$ and calving difficulty $(P=0.04)$.

Within the first $60 \mathrm{~d}$ of lactation, $7.8 \%$ of animals were culled $(\mathrm{n}=76)$. No effect was found of treatment on the odds of being culled in the first $60 \mathrm{~d}$ (odds ratio $=0.95,95 \%$ CI 0.58 to 1.55 ) after accounting for BCS $(P<0.0001)$ and parity $(P<0.01)$. Among the 657 animals with a blood sample collected at enrollment, the model included tCa0 $(P<0.01)$ and BCS $(P<$ $0.0001)$, but no effect of treatment $(P=0.6)$ was observed.

\section{Effect of Treatment on Milk Production}

Covariates retained in each of the models for 24-h milk yield at each of the first 3 DHIA test days included farm as a fixed effect $(P<0.0001)$, parity $(P<$ $0.0001)$, fat percentage $(P<0.002)$, protein percentage $(P<0.04)$, and linear SCS $(P<0.01)$. Treatment had no effect on milk production in any of the 3 test day models $(P>0.13)$ and no interactions with treatment were found. For the subset of cows in second or greater lactation $(\mathrm{n}=576)$, previous mature-equivalent 305-d milk production (ME305) was offered to each test day model as a covariate. The variable was retained in all 3 models $(P<0.0001)$ in addition to the variables listed above but did not have an interaction with treatment and the effect of treatment on milk production was unchanged $(P>0.45)$. Similarly, in the repeated measures model for (all 3 DHIA tests together) and the projected 305-d milk yield model, treatment had no effect on milk production.

\section{Effect of Treatment on Reproductive Success}

Among the 784 animals that were rebred, the probability of pregnancy to first AI was $47 \%$. No interactions

Table 3. Description of covariates and disease outcomes in 984 Holstein cows randomly assigned to receive 2 injections of a commercial Ca supplement (total of $240 \mathrm{~mL}$ of SC within approximately $24 \mathrm{~h}$ after calving) or placebo

\begin{tabular}{|c|c|c|c|}
\hline \multirow[b]{2}{*}{ Variable } & \multicolumn{2}{|c|}{$\%$ of cows } & \multirow[b]{2}{*}{$P$-value } \\
\hline & $\begin{array}{l}\text { Treatment } \\
(\mathrm{n}=518)\end{array}$ & $\begin{array}{c}\text { Control } \\
(\mathrm{n}=466)\end{array}$ & \\
\hline Parity & & & 0.43 \\
\hline 1 & 52 & 48 & \\
\hline 2 & 56 & 44 & \\
\hline$\geq 3$ & 51 & 49 & \\
\hline Twins & 5 & 5 & 0.94 \\
\hline Dystocia $^{1}$ & 17 & 16 & 0.71 \\
\hline Retained placenta & 7 & 6 & 0.84 \\
\hline Metritis & 4 & 3 & 0.20 \\
\hline BCS at enrollment & & & 0.11 \\
\hline Thin $(\leq 2.75)$ & 21 & 15 & \\
\hline Moderate (3-3.5) & 73 & 79 & \\
\hline Fat $(\geq 3.75)$ & 6 & 6 & \\
\hline Received additional Ca & 5 & 8 & 0.03 \\
\hline Ketosis (blood BHB $\geq 1.2 \mathrm{mmol} / \mathrm{L})$ at wk 1 (3-9 DIM) & 15 & 13 & 0.18 \\
\hline Ketosis (blood BHB $\geq 1.2 \mathrm{mmol} / \mathrm{L})$ at wk $2(10-16$ DIM $)$ & 16 & 13 & 0.12 \\
\hline Ketosis, 3-16 DIM (cumulative) & 22 & 20 & 0.35 \\
\hline Displaced abomasum & 2 & 0.6 & 0.08 \\
\hline Culling $\leq 60$ DIM & 8 & 8 & 0.81 \\
\hline Purulent vaginal discharge & 12 & 14 & 0.28 \\
\hline
\end{tabular}

${ }^{1}$ Dystocia defined as a calving difficulty score greater than 1: $1=$ unassisted, $2=$ easy pull (one person, $<15$ min), $3=$ hard pull (>15 min, use of calving jack or multiple people), $4=$ cesarean section. 


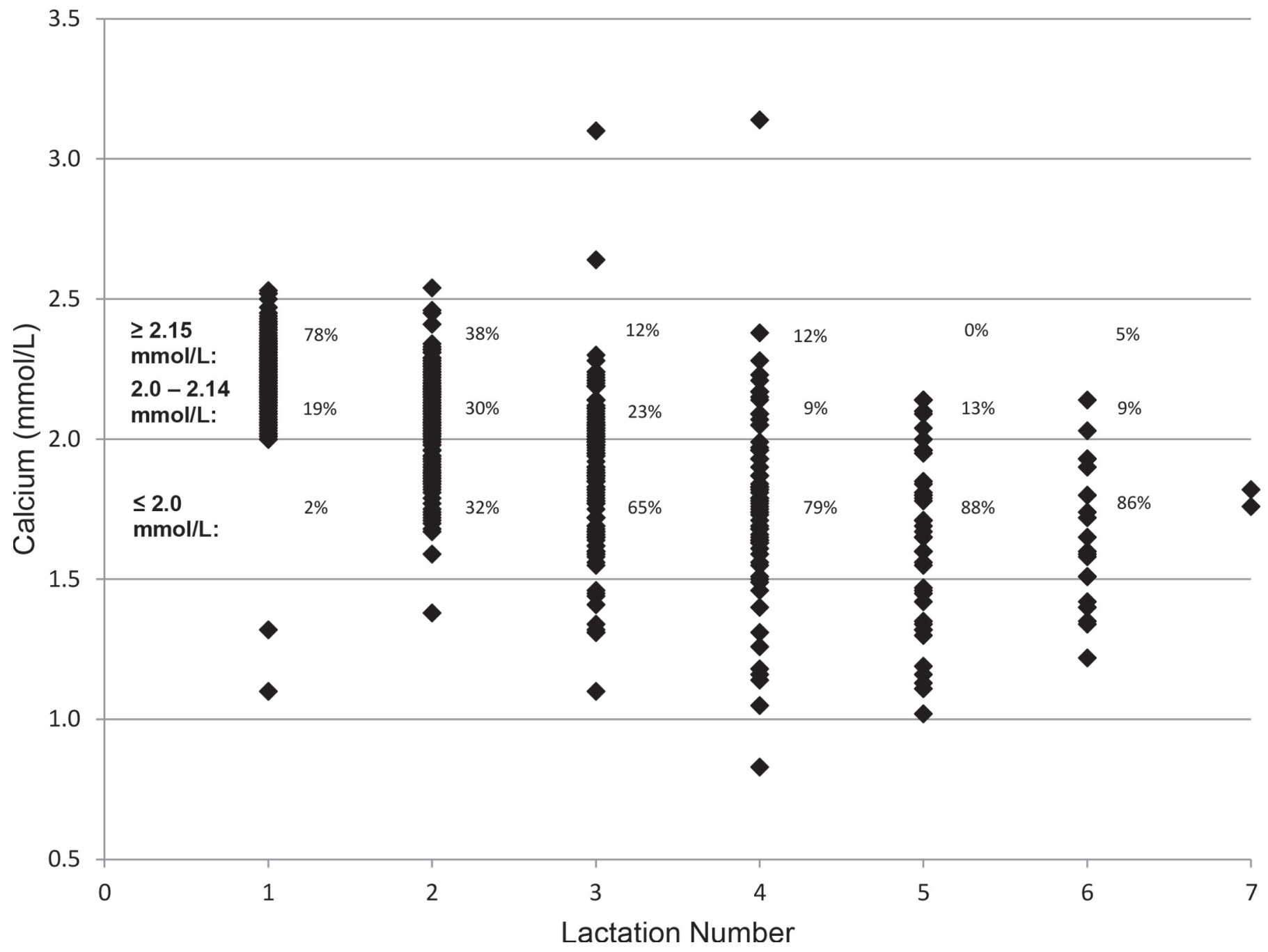

Figure 2. Distribution of serum total Ca concentration by parity at the time of enrollment (approximately 1 to $8 \mathrm{~h}$ after calving) for 657 Holstein cows in a randomized controlled trial of an injectable Ca supplement.

were found with treatment, and treatment had no effect on pregnancy at first insemination after accounting for BCS at enrollment $(P=0.02)$. The model of the effect of treatment on time to pregnancy model retained the variables farm (as a fixed effect; $P<0.0001$ ) and parity $(P<0.001)$. Treatment had no effect on time to

Table 4. Final model for clinical hypocalcemia requiring additional Ca treatment in 984 Holsteins from 7 herds

\begin{tabular}{lccccc}
\hline Variable & $\beta$ & $\mathrm{SE}$ & $P$-value & Odds ratio & $95 \%$ CI \\
\hline $\begin{array}{l}\text { Intercept } \\
\text { Study group }\end{array}$ & -0.03 & 0.40 & 0.95 & - & - \\
$\begin{array}{l}\text { Treatment } \\
\text { Control }\end{array}$ & $\begin{array}{c}-0.60 \\
\text { Referent }\end{array}$ & 0.28 & 0.03 & 0.55 & 0.32 to 0.95 \\
$\begin{array}{l}\text { Parity } \\
1\end{array}$ & -3.96 & 1.01 & 0.0001 & 0.02 & - \\
2 & -1.54 & 0.40 & 0.0001 & 0.21 & 0.003 to 0.14 \\
$3+$ & Referent & - & - & - & - \\
Twins & -1.70 & 0.40 & $<0.0001$ & 0.18 & 0.08 to 0.40 \\
0 & Referent & - & - & - & - \\
\hline
\end{tabular}


pregnancy $(P=0.53)$. The median time to pregnancy (95\% CI) was 108 (96 to 121) d in the treatment group and 96 (89 to 113) d in the control group.

\section{DISCUSSION}

The purpose of this study was to evaluate the effect of an approved (in Canada) Ca supplementation product on blood $\mathrm{Ca}$ concentrations, clinical disease, culling, milk production in early lactation, and probability of pregnancy. This is the first large-scale study to examine the subcutaneous prophylactic administration of $\mathrm{Ca}$ after calving. The population of cows used for the study were purposively chosen from farms willing to participate and comply with the protocol. These were well-managed farms with good animal husbandry and animal health, but without negative DCAD diets for prefresh cows.

We have not found evidence in the literature that blood tCa $<2.0 \mathrm{mmol} / \mathrm{L}$ (e.g., Reinhardt et al., 2011) is associated with increased risk of undesirable outcomes. Nevertheless, for comparison using the traditional cut point of $2.0 \mathrm{mmol} / \mathrm{L}$, the prevalence of $\mathrm{SCH}$ approximately 1 to $8 \mathrm{~h}$ after calving was $38 \%$ in the animals enrolled with a blood sample at calving. Among third or greater parity cows only, the prevalence of hypocalcemia using this cut point was $57 \%$. Although not a random sample of the population, these findings are similar to those reported in Reinhardt et al. (2011) for second and greater lactation cows. Reinhardt et al. (2011) reported a prevalence of $25 \% \mathrm{SCH}$ in first lactation animals, whereas we found only $1 \%$ of animals with tCa $<2.0 \mathrm{mmol} / \mathrm{L}$. However, Reinhardt et al. (2011) took samples over the first $48 \mathrm{~h}$, whereas in the present study samples were collected at the time of enrollment after calving, which does not include the typical nadir of blood Ca between 12 and $24 \mathrm{~h}$ after calving (Goff, 2008).

A large majority of the time-of-enrollment samples came from one larger herd, so generalizations must be made with caution. However, no studies report the prevalence of $\mathrm{SCH}$ immediately after calving in Canadian dairy cattle. A previous study collected blood samples once weekly between 1 and $7 \mathrm{~d}$ after calving from 24 dairy farms in Ontario and reported that 5.8\% of animals were below $2.0 \mathrm{mmol} / \mathrm{L}$ during this time (Seifi et al., 2011). A window of 1 to 7 DIM may not capture cows that had hypocalcemia initially, which resolved within the first 2 to 3 DIM as was evident for many cows in the current study. Martinez et al. (2012) found that cows with blood Ca less than $2.15 \mathrm{mmol} / \mathrm{L}$ at least once during the first 3 DIM had impaired neutrophil function and increased incidence of metritis. Using this cut point, $72 \%$ of 129 cows tested repeatedly after calving in our study were below $2.15 \mathrm{mmol} / \mathrm{L}$ at one or more of 3 tests in the $48 \mathrm{~h}$.

With this subcutaneous prophylactic Ca protocol, blood Ca levels were temporarily increased at $24 \mathrm{~h}$ after treatment. Accounting for pretreatment blood $\mathrm{Ca}$ and its interaction with treatment, on average, half of the treatment increased blood Ca by $0.13 \pm 0.04 \mathrm{mmol} / \mathrm{L}$. Among treated cows there was a greater rise in tCa for cows with lower tCa0 compared with cows with a higher tCa0. Biologically, these cows are in greater need of $\mathrm{Ca}$ to re-establish $\mathrm{Ca}$ homeostasis compared with cows with higher blood $\mathrm{Ca}$ at the time of calving. Based on the model (Table 3), treatment did not increase tCa24 among cows with tCa $02.4 \mathrm{mmol} / \mathrm{L}$, but very few cows in the study had levels this high $(\mathrm{n}=26,2.6 \%)$.

The goal of prophylactic administration of $\mathrm{Ca}$ is to mitigate the Ca nadir that occurs between 12 and $24 \mathrm{~h}$ after calving (Goff, 2008) when Ca demand has spiked and homeostasis strategies are not yet fully functional. Cows may begin to show signs of stage I MF in the range of 1.4 to $1.9 \mathrm{mmol} / \mathrm{L}$ (Oetzel, 2011), but the exact tCa at which a cow exhibits clinical signs is not consistent. According to our results (Figure 1), cows in this range would experience a 0.18 to $0.33 \mathrm{mmol} / \mathrm{L}$ increase in $\mathrm{tCa}$ in response to treatment, which may be enough to mitigate early MF signs in some cows. This may be reflected in the lower proportion of animals in the treatment group that were treated for clinical hypocalcemia.

Producers were able to give additional Ca therapy to enrolled cows only if these cows showed signs of hypocalcemia such as trembling, weakness, or recumbence. It is presumed that the 29 cows treated with subcutaneous or oral Ca only were showing stage I hypocalcemia signs, whereas the 36 cows that received intravenous Ca alone or with subcutaneous or oral $\mathrm{Ca}$ may represent cows showing signs of either stage I or stage II (sternal recumbence) hypocalcemia. Producers were blinded to the treatment given to prevent bias for this outcome in particular. Of the 65 animals that received additional Ca therapies for MF, significantly more $(60 \%)$ were in the control group.

The increased risk for disease, poorer immune function, and production losses associated with lower tCa in the days after calving (Chapinal et al., 2011, 2012; Martinez et al., 2012) suggests that mitigating hypocalcemia would be advantageous. Treated cows were not more likely to be above the cut point of $2.15 \mathrm{mmol} / \mathrm{L}$ from Martinez et al. (2012), at 24 or $48 \mathrm{~h}$ after enrollment. A $0.13 \mathrm{mmol} / \mathrm{L}$ average increase in tCa from 0 to $24 \mathrm{~h}$ was insufficient for most cows to reach 2.15 $\mathrm{mmol} / \mathrm{L}$ based on tCa0. This did not increase blood $\mathrm{Ca}$ to a threshold that is predicted to have effects on immune function and risk of disease based on other 
reported studies (Chapinal et al., 2011; Martinez et al., 2012).

In accordance with this prediction, no effect was found of treatment on any of the disease, milk production, or reproduction outcomes. No other controlled trials are available on subcutaneous Ca supplementation with which to compare these results; however, Melendez et al. (2002) and Oetzel and Miller (2012) found no effects of 2 different oral Ca supplements on blood Ca concentration, early lactation health, or milk yield in cows supplemented with anionic salts. Oetzel and Miller (2012) reported very low levels of MF $(0.6 \%)$ and hypocalcemia (14\% of cows with ionized $\mathrm{Ca} \leq 1.0$ $\mathrm{mmol} / \mathrm{L}$ between 8 and $35 \mathrm{~h}$ after calving) in the 2 herds used so there may have been less opportunity to mitigate hypocalcemia. The present study differs from those above in that none of our herds were fed anionic salts prepartum and the incidence of MF $(6.6 \%)$ and $\mathrm{SCH}$ (43\%, using a similar cut point of total $\mathrm{Ca}<2.0$ $\mathrm{mmol} / \mathrm{L}$ between 0 and $8 \mathrm{~h}$ among cows of parity $\geq 2$ ), was considerably higher; however, no effect of treatment was found on any of these outcomes.

A tCa of $\leq 2.2 \mathrm{mmol} / \mathrm{L}$ in the first week after calving was associated with 2.7 greater odds of DA in a large sample of herds across Canada and the United States (Chapinal et al., 2011). Prophylactic Ca treatment might therefore be hypothesized to reduce the risk of DA, but only Oetzel (1996) found reduced incidence of DA among cows of all parities treated with 3 to 4 doses of $\mathrm{CaCl}_{2}$ gel (54 g of elemental Ca/dose) at 12-h intervals beginning $12 \mathrm{~h}$ before predicted calving $(\mathrm{n}=$ 204). Other controlled studies using prophylactic Ca found no effect of treatment on the incidence of DA (Hernandez et al., 1999; Melendez et al., 2003; Oetzel and Miller, 2012). The current study had a very low incidence of DA (1.3\%), which was verified at weekly visits by study personnel but did not provide an adequate sample size to examine risk despite enrolling almost 1,000 cows.

Martinez et al. (2012) found that cows with tCa $<2.15$ $\mathrm{mmol} / \mathrm{L}$ between 1 and 3 DIM were at increased risk of metritis compared with cows that maintained higher tCa. Therefore, Ca therapies that maintain normocalcemia might have an effect on metritis. The incidence of metritis in this study was $3.4 \%$, which is low compared with other reported studies (Kelton et al., 1998; Chapinal et al., 2011) and might indicate under-reporting despite giving producers a standardized disease definition (systemic illness including fever $>39.5^{\circ} \mathrm{C}$ with fetid discharge) and verifying against treatment records. Cows in the study herds were observed frequently but rectal temperature taken only if daily observation indicated illness. This approach may have diagnosed fewer cows than a systematic daily fresh cow examination would find. However, with only 7 herds, it is possible this is normal for these well-managed herds. Prophylactic Ca treatment had no effect on the incidence of metritis. Hernandez et al. (1999) studied cows with RP and did not find an effect of $\mathrm{Ca}$ prophylaxis on metritis). A preliminary report of a controlled trial indicated that $\mathrm{SC}$ injection of Ca borogluconate increased blood tCa and a 2-injection regimen with timing similar to the present study decreased the odds of metritis (Amanlou et al., 2015).

Early lactation is a time of higher risk for cows to leave the herd. Data from 4134 dairy cows in Canada and the United States indicated that $\mathrm{Ca} \leq 2.2 \mathrm{mmol} / \mathrm{L}$ in the first week after calving was associated with 1.5 times greater odds of culling in early lactation compared with cows above the threshold (Roberts et al., 2012). Similar to Oetzel and Miller (2012), we found no effect of prophylactic Ca treatment on culling even though tCa0 was an important predictor of culling risk. The lack of treatment effect on culling is not surprising given the absence of effect on other transition disease outcomes that likely more directly influence culling risk in early lactation.

Chapinal et al. (2012) found that cows with $\mathrm{Ca} \leq 2.1$ $\mathrm{mmol} / \mathrm{L}$ in the first week after calving had lower average milk production at the first DHIA test with an estimated reduction of $2.6 \mathrm{~kg} / \mathrm{d}$. No treatment effects on milk production were identified in the current study. Likewise, Melendez et al. (2003) did not find any improvement in milk yield for cows fed anionic salts before calving and treated with oral $\mathrm{CaCl}_{2}$ gel. In contrast, Oetzel and Miller (2012) found that cows with a higher previous lactation mature-equivalent milk production (greater than $105 \%$ of herd average) supplemented with oral Ca boluses produced $2.9 \mathrm{~kg}$ more milk at first test, but no treatment effects in other subpopulations or on other early lactation outcomes. It is not known if any effect would be realized using the present treatment in a population with a lower prevalence of hypocalcemia, similar to the herds in Oetzel and Miller (2012) that were fed an acidified diet. It could be hypothesized that cows need to be closer to the biological threshold of $2.15 \mathrm{mmol} / \mathrm{L}$ associated with effects on immune function and risk of disease (Chapinal et al., 2011; Martinez et al., 2012) to realize production benefits of supplementation.

Minimizing postpartum reproductive disease and promptly returning to cyclicity is essential to ensuring subsequent pregnancy. Caixeta et al. (2015) reported that cows that remained normocalcemic in the first $3 \mathrm{~d}$ after calving had higher levels of progesterone in the first 55 DIM and resumed ovarian activity earlier than hypocalcemic cows. Additionally, in a large North American study (Chapinal et al., 2012), cows with 
lower serum $\mathrm{Ca}$ in the week before or after calving had reduced odds of pregnancy at first service. Although MF has been associated with PVD (Whiteford and Sheldon, 2005), in the present study, treatment did not affect the prevalence of PVD between 4 and 6 wk after calving, which might be expected because tCa0 was not associated with PVD in this study. No other Ca prophylaxis studies have examined this outcome. Similarly, no effect was found of treatment on pregnancy at first service or time to pregnancy. Other Ca supplementation studies that have looked at reproductive outcomes have found no effect of $\mathrm{Ca}$ treatment. Hernandez et al. (1999) found no effect of $\mathrm{CaCl}_{2}$ gel treatment on pregnancy at first $\mathrm{AI}$ in a small sample of cows $(\mathrm{n}=$ 60) where one-third of cows enrolled had an RP, but study power limited their ability to detect a difference. Similar to our findings, a large $(\mathrm{n}=927)$ oral Ca bolus supplementation study (Oetzel and Miller, 2012) found no difference in time to pregnancy.

\section{CONCLUSIONS}

Prophylactic use of 2 doses of subcutaneous Ca was effective in modestly increasing serum $\mathrm{Ca}$ concentrations in the first day after calving and reduced the proportion of cows that received supplemental Ca because they exhibited clinical signs of hypocalcemia. Under the treatment regimen studied, no effect was found of supplemental $\mathrm{Ca}$ on the risk of disease or culling, milk production, or reproductive performance.

\section{ACKNOWLEDGMENTS}

This study was funded by Vetoquinol Canada with stipend support from the Ontario Ministry of Agriculture, Food and Rural Affairs (OMAFRA, Canada). The authors thank the participating farms, technicians, and students.

\section{REFERENCES}

Amanlou, H., A. Pourakbari, N. Silva del Rio, and N. E. Farsuni. 2015. Effects of prophylactic subcutaneous calcium treatment at calving on macro mineral status and health of Holstein cows. J. Dairy Sci. 98(Suppl. 2):475. (Abstr.)

Blanc, C. D., M. Van der List, S. S. Aly, H. A. Rossow, and N. Silvadel-Rio. 2014. Blood Ca dynamics after prophylactic treatment of subclinical hypocalcemia with oral or intravenous Ca. J. Dairy Sci. 97:6901-6906. http://dx.doi.org/10.3168/jds.2014-7927.

Caixeta, L. S., P. A. Ospina, M. B. Capel, and D. V. Nydam. 2015. The association of subclinical hypocalcemia, negative energy balance and disease with bodyweight change during the first 30 days post-partum in dairy cows milked with automatic milking systems. Vet. J. 204:150-156. http://dx.doi.org/10.1016/j.tvjl.2015.01.021.

Chamberlin, W. G., J. R. Middleton, J. N. Spain, G. C. Johnson, M. R. Ellersieck, and P. Pithua. 2013. Subclinical hypocalcemia, plasma biochemical parameters, lipid metabolism, postpartum disease, and fertility in postparturient dairy cows. J. Dairy Sci. 96:7001-7013. http://dx.doi.org/10.3168/jds.2013-6901.

Chapinal, N., M. Carson, T. F. Duffield, M. Capel, S. Godden, M. Overton, J. E. Santos, and S. J. LeBlanc. 2011. The association of serum metabolites with clinical disease during the transition period. J. Dairy Sci. 94:4897-4903. http://dx.doi.org/10.3168/ jds.2010-4075.

Chapinal, N., M. E. Carson, S. J. LeBlanc, K. E. Leslie, S. Godden, M. Capel, J. E. Santos, M. W. Overton, and T. F. Duffield. 2012. The association of serum metabolites in the transition period with milk production and early-lactation reproductive performance. J. Dairy Sci. 95:1301-1309. http://dx.doi.org/10.3168/jds.2011-4724.

DeGaris, P. J., and I. J. Lean. 2008. Milk fever in dairy cows: A review of pathophysiology and control principles. Vet. J. 176:58-69.

Ferguson, J. D., D. T. Galligan, and N. Thomsen. 1994. Principal descriptors of body condition score in Holstein cows. J. Dairy Sci. 77:2695-2703.

Goff, J. P. 1999. Treatment of Ca, phosphorus, and magnesium balance disorders. Vet. Clin. North Am. Food Anim. Pract. 15:619-639.

Goff, J. P. 2008. The monitoring, prevention, and treatment of milk fever and subclinical hypocalcemia in dairy cows. Vet. J. 176:50-57.

Goff, J. P., and R. L. Horst. 2003. Role of acid-base physiology on the pathogenesis of parturient hypocalcaemia (milk fever)-The DCAD theory in principal and practice. Acta Vet. Scand. Suppl. 97:51-56.

Hernandez, J., C. A. Risco, and J. B. Elliott. 1999. Effect of oral administration of a Ca chloride gel on blood mineral concentrations, parturient disorders, reproductive performance, and milk production of dairy cows with retained fetal membranes. J. Am. Vet. Med. Assoc. 215:72-76.

Iwersen, M., U. Falkenberg, R. Voigtsberger, D. Forderung, and W. Heuwieser. 2009. Evaluation of an electronic cowside test to detect subclinical ketosis in dairy cows. J. Dairy Sci. 92:2618-2624. http://dx.doi.org/10.3168/jds.2008-1795.

Kelton, D. F., K. D. Lissemore, and R. E. Martin. 1998. Recommendations for recording and calculating the incidence of selected clinical diseases of dairy cattle. J. Dairy Sci. 81:2502-2509.

Kimura, K., T. A. Reinhardt, and J. P. Goff. 2006. Parturition and hypocalcemia blunts Ca signals in immune cells of dairy cattle. J. Dairy Sci. 89:2588-2595.

LeBlanc, S. J., T. F. Duffield, K. E. Leslie, K. G. Bateman, J. TenHag, J. S. Walton, and W. H. Johnson. 2002. The effect of prepartum injection of vitamin $\mathrm{E}$ on health in transition dairy cows. J. Dairy Sci. 85:1416-1426.

Martinez, N., C. A. Risco, F. S. Lima, R. S. Bisinotto, L. F. Greco, E. S. Ribeiro, F. Maunsell, K. Galvao, and J. E. Santos. 2012. Evaluation of peripartal Ca status, energetic profile, and neutrophil function in dairy cows at low or high risk of developing uterine disease. J. Dairy Sci. 95:7158-7172. http://dx.doi.org/10.3168/ jds.2012-5812.

McDougall, S., R. Macaulay, and C. Compton. 2007. Association between endometritis diagnosis using a novel intravaginal device and reproductive performance in dairy cattle. Anim. Reprod. Sci. 99:9-23.

McLaren, C. J., K. D. Lissemore, T. F. Duffield, K. E. Leslie, D. F. Kelton, and B. Grexton. 2006. The relationship between herd level disease incidence and a return over feed index in Ontario dairy herds. Can. Vet. J. 47:767-773.

Melendez, P., A. Donovan, C. A. Risco, M. B. Hall, R. Littell, and J. Goff. 2002. Metabolic responses of transition Holstein cows fed anionic salts and supplemented at salving with Ca and energy. J. Dairy Sci. 85:1085-1092.

Melendez, P., G. A. Donovan, C. A. Risco, R. Littell, and J. P. Goff. 2003. Effect of Ca-energy supplements on calving-related disorders, fertility and milk yield during the transition period in cows fed anionic diets. Theriogenology 60:843-854.

Mohebbi-Fani, M., and P. Azadnia. 2012. The effect of subcutaneous injection of calcium borogluconate on serum levels of calcium, phosphorus and magnesium in newly calved cows. Comp. Clin. Pathol. 21:1647-1652. 
Oetzel, G. R. 1996. Effect of Ca chloride gel treatment in dairy cows on incidence of periparturient diseases. J. Am. Vet. Med. Assoc. 209:958-961.

Oetzel, G. R. 2011. Non-infectious diseases: Milk Fever. Pages 239-245 in Encyclopedia of Dairy Sciences. Vol. 2. J. W. Fuquay and P. L. McSweeney, ed. Academic Press, San Diego, CA.

Oetzel, G. R. 2013. Oral Ca supplementation in peripartum dairy cows. Vet. Clin. North Am. Food Anim. Pract. 29:447-455. http:// dx.doi.org/10.1016/j.cvfa.2013.03.006.

Oetzel, G. R., and B. E. Miller. 2012. Effect of oral Ca bolus supplementation on early-lactation health and milk yield in commercial dairy herds. J. Dairy Sci. 95:7051-7065. http://dx.doi. org/10.3168/jds.2012-5510.

Raboisson, D., M. Mounie, and E. Maigne. 2014. Diseases, reproductive performance, and changes in milk production associated with subclinical ketosis in dairy cows: A meta-analysis and review. J. Dairy Sci. 97:7547-7563. http://dx.doi.org/10.3168/jds.2014-8237.

Reinhardt, T. A., J. D. Lippolis, B. J. McCluskey, J. P. Goff, and R. L. Horst. 2011. Prevalence of subclinical hypocalcemia in dairy herds. Vet. J. 188:122-124. http://dx.doi.org/10.1016/j.tvjl.2010.03.025.
Roberts, T., N. Chapinal, S. J. LeBlanc, D. F. Kelton, J. Dubuc, and T. F. Duffield. 2012. Metabolic parameters in transition cows as indicators for early-lactation culling risk. J. Dairy Sci. 95:30573063. http://dx.doi.org/10.3168/jds.2011-4937.

Sampson, J. D., J. N. Spain, C. Jones, and L. Carstensen. 2009. Effects of $\mathrm{Ca}$ chloride and $\mathrm{Ca}$ sulfate in an oral bolus given as a supplement to postpartum dairy cows. Vet. Ther. 10:131-139.

Seifi, H. A., S. J. LeBlanc, K. E. Leslie, and T. F. Duffield. 2011 Metabolic predictors of post-partum disease and culling risk in dairy cattle. Vet. J. 188:216-220. http://dx.doi.org/10.1016/j. tvjl.2010.04.007.

Sheldon, I. M., G. S. Lewis, S. LeBlanc, and R. O. Gilbert. 2006. Defining postpartum uterine disease in cattle. Theriogenology $65: 1516-1530$

Whiteford, L. C., and I. M. Sheldon. 2005. Association between clinical hypocalcaemia and postpartum endometritis. Vet. Rec. 157:202-203. 